\title{
A BURIAL GRAVE AT TELL KEILA, PALESTINE
}

\author{
S. Manzano Fernández ${ }^{1,3}$ *, F. Vegas ${ }^{2,3}$, V. Cristini ${ }^{2,3}$, A. Hueto Escobar ${ }^{2,3}$ \\ ${ }^{1}$ Architect, Master in Preservation of Architectural Heritage, Universitat Politècnica de València, Spain - sermanfe@arq.upv.es \\ ${ }^{2}$ Department of Architectural Composition, Universitat Politècnica de València, Spain - \\ (fvegas, vacri)@cpa.upv.es, alhuees@upv.es \\ ${ }^{3}$ Research Centre PEGASO, Universitat Politècnica de València, Valencia, Spain
}

Commission II - WG II/8

KEY WORDS: Burial grave, Tomb, Funeral architecture, Survey, Tell Keila, Palestinian Territories

\begin{abstract}
:
The recent excavation of the Tell Keila archaeological site in the Hebron Governorate (Palestine) has revealed new burial graves among the already known in the region of Judea (Yezerski, 2013), providing innovative guidelines for understanding the scope of the funeral typology which was characteristic of the Second Iron Age and Hellenistic, Roman and Byzantian periods and their subsequent occupations. 49 tombs have been inventoried in total, among which it is worth noting the largest, number 26, which is located in the immediate surroundings of the Tell. Its rich architecture has enabled a more comprehensive study and comparison, and when the excavation campaign ended in 2018 numerous elements characteristic of the funeral customs, local ways of life at the time, and state of conservation of the construction had been identified. The geometry and spaces were exactly identified with a complete metric and photo-rectified survey of the tomb which took into consideration the limitations imposed on the work by the local socio-cultural and socio-economic context.
\end{abstract}

\section{INTRODUCTION}

\subsection{Burial graves in the Middle East}

The burial grave is one of the most characteristic typologies of the ethnic identity of Palestine, and is part of the funeral customs of the early civilizations which spread throughout the East, including Egypt, Jordan, Syria, Lebanon, and Israel (Corner, Kitchener, 1881-1883) (Guérin, 1869). Its excavation and study therefore contributes to the understanding of these practices, identifying occupation periods and their origin based on archaelogical typologies and remains.

In this regard, the Tell Keila archaeological complex had undergone no excavation or architectural documenting process until the start of the Keila Project in 2014-2015 (through some initial geophysical studies by the Institut de Physique du Globe de Strasbourg), so that this analysis may provide important information that contributes to understanding the site and its place in history.

\subsection{Tell Keila archaeological site}

Tell Keila is located in the mountainous area of the Judaean Mountains, in the southwest part of the West Bank, on the outskirts of the town of Beit Ula, approximately $25 \mathrm{~km}$ from Jerusalem. The site in the district of Hebron had the first known reference in the Middle Bronze Age when it was mentioned as a strategic city-state of great local importance (Bert, S., Abu, C., 2016). There are other mentions dating from the 5th century, when historian Sozomen (HE, VII, 29, 2) explains how the old necropolis was found. Over thirty burial sites from the Second Iron Age have been inventoried since then (Yezerski, 1999).

Morphologically speaking, the term 'Tell' refers to the artificial hill created by ruins superimposed with eroded materials, while the origin of 'Keila' is more complex, with variants of the term -
Qiltu, Keilah, Qila, and Kirbeit Qeila - appearing in different languages (Zamudio, 2008).

This large terraced complex includes fortresses from the Middle Bronze Age, with masonry and four towers. In total, 49 burial graves have been identified on its slopes and immediate surroundings, with some sharing common elements, with configurations in various different sizes. Five sectors were also excavated, and Sector 5, located on the flat top of the hill (Sector 5 ), was found to include other typologies which were assumed to be religious and residential.

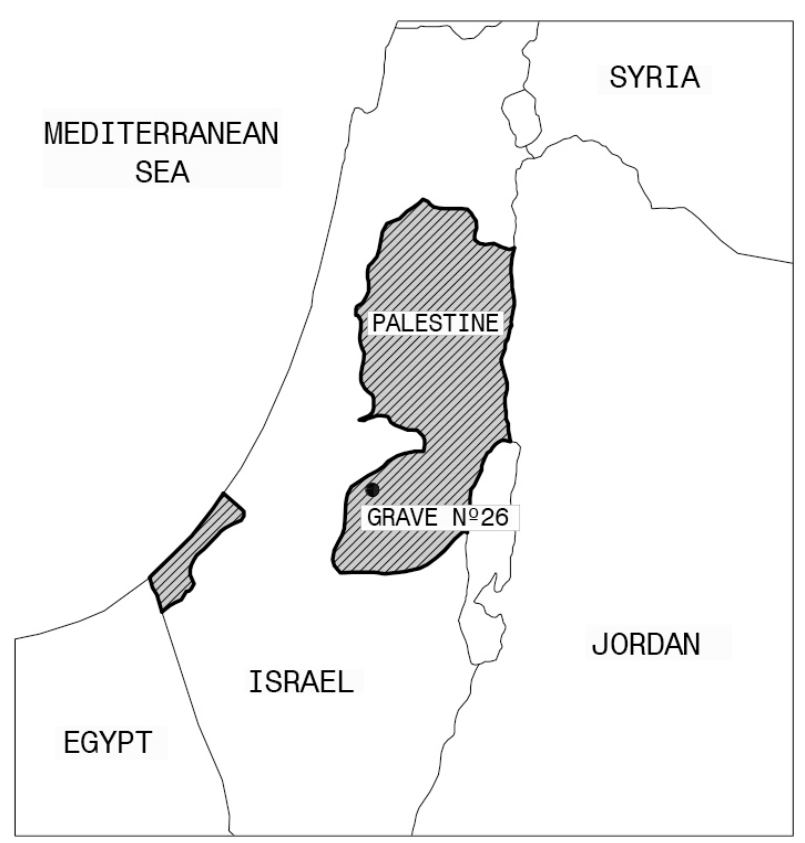

Figure 1. Location of the site.

* Corresponding author 
Of all the complexes, grave number 26 was studied in most detail as its size and the scale of the construction were felt to be of greater architectural interest (Figure 1).

\subsection{Historical and topographical context}

Grave number 26 is the largest and most elaborate of all the analyzed ones, and therefore numerous burial elements can be established. It is located in the northwest of the Tell site, approximately 250 metres from the very centre and separated from the site by one of the local roads. This road leads onto the path for accessing the entrance, on the slope and overlooking the landscape, so that it is accessible to all types of transport.

The excavation began in 2017, together with a rough survey of its ground plan (Blétry, 2018) and both processes were completed during the 2018 campaign. This tomb is thought to have been occupied in the Hellenistic, Roman (Herodian) and Byzantian periods (Blétry, 2018), to judge from the ceramic remains with burial elements characteristic to periods after the Iron Age ('kokhim'), and its architecture shows similarities to other contemporary examples in Jerusalem, with antechambers and one or several rooms. The nature of the degradations observed when surveying and analysing the space suggest that the complex was recently occupied, and fires lit in the interior have almost completely covered the walls of the antechamber with soot and accelerated the loss of material and the constructive section.

\subsection{Architectural survey}

The creation of information, graphic documentation and analysis of this tomb was carried out in two phases during the excavation campaign. The first consisted of fieldwork in direct contact with architectural remains, while the second focused on processing, treating, and compiling information.

In view of the technological limitations stemming from the location's socio-economic and social conditions the proposed project was to promote heritage using traditional data collection, analysing the topography with the LEICA TCR 407 station and photo-rectification of the parallel planes. As it was impossible to use remote acquisition techniques such as $3 \mathrm{D}$ scanners, rectification provides an alternative to help understand some of the elements and complement the measurement.

Given the organic nature of the most deteriorated surfaces manual construction tools were necessary to establish level vertical and horizontal lines of reference. The images were obtained using a camera and calibrated photogrammetry rectification software.

\section{BURIAL GRAVE 26}

\subsection{Cave no. 26}

The complex takes the form of a rock-cut tomb and a huge mass of the soft local limestone which is relatively easy to dig out, has been hewn out to create the desired interior architectural and functional spaces. In contrast, its duration is less than those more compact such as granite, which does not ensure its continuity over time. It is carved out from the stone bank on the slope using tools, such as chisels, pickaxes or drills, to rough down the hard rock.

The direction follows that of the seam of the stone, to facilitate the hollowing out of the spaces of burial chamber and morturay elements as well as save several working time.

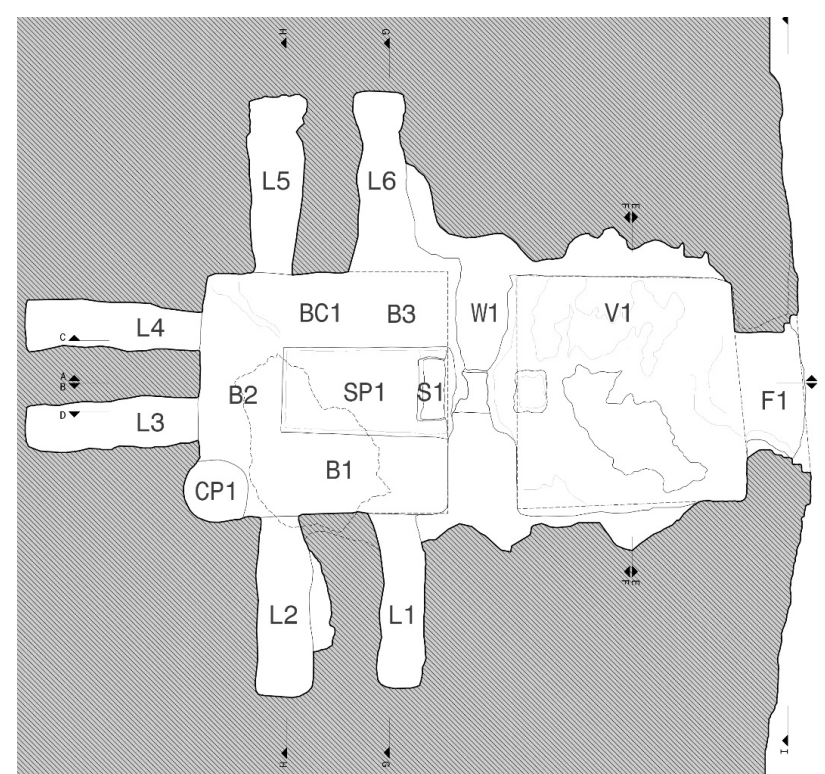

Figure 2. Cave no. 26: plan of the grave.

Inside, the tomb occupies $44.50 \mathrm{~m}^{2}$ running from east to west to develop two very distinct and recognizable architectural spaces: an antechamber and a primary burial chamber (Figure 2). These were originally physically separated by a wall, which has now been lost in one of many collapses so that the resulting continuous spatial concepts differ radically from the original design of the cave.

The tomb falls under the two major typologies for local burial chambers, as it has representative elements from both: the benches and shelves and the niches ('kokh') (Yezerski, 1999). However, it is possible to list and identify a series of elements characteristic of this type of architecture (Kloner and Zissu, 2007) which appeared due to the economic and cultural factors of the owner families or the periods of occupation of the building.

2.2.1 The courtyard: A common solution for the burial typology is the existence of a courtyard leading to the entrance, usually taking the form of a flat surface in front of it. As the entrance to the tomb was modified in 1997 (Blétry, 2018), it is impossible to establish the exact original characteristics of the space. Furthermore there are currently no traces of its existence, with an original continuous façade approximately 0.60 metres long at either side, revealing a notable loss of section by layers of rock.

2.2.2 The tomb façade (F1): The complex has an entrance to the vestibule with an ornate façade, that is, a vertical plane containing the access to the interior space where a double recessed plane is carved out, staggered in relation to the original and currently only preserved in its upper section (Figure 3 ). The first of these usually served as an enclosure fitted with a slab (the closing or blocking stone), unlikely in this case given the dimensions and function of the previous room, while the successive carvings were included only for merely aesthetic and decorative purposes.

The measurements of the opening, 1.75 meters high by 1.35 meters wide, are head height, and bases of the jambs are partially deteriorated, with a notable loss of constructive section. 


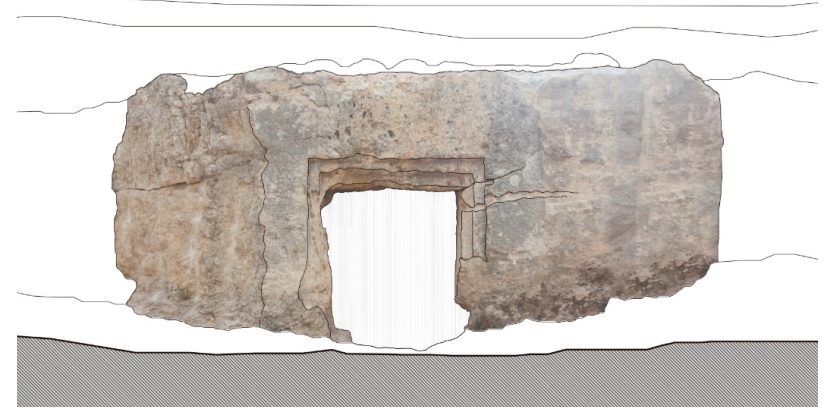

Figure 3. Tomb façade: main section of the entrance.
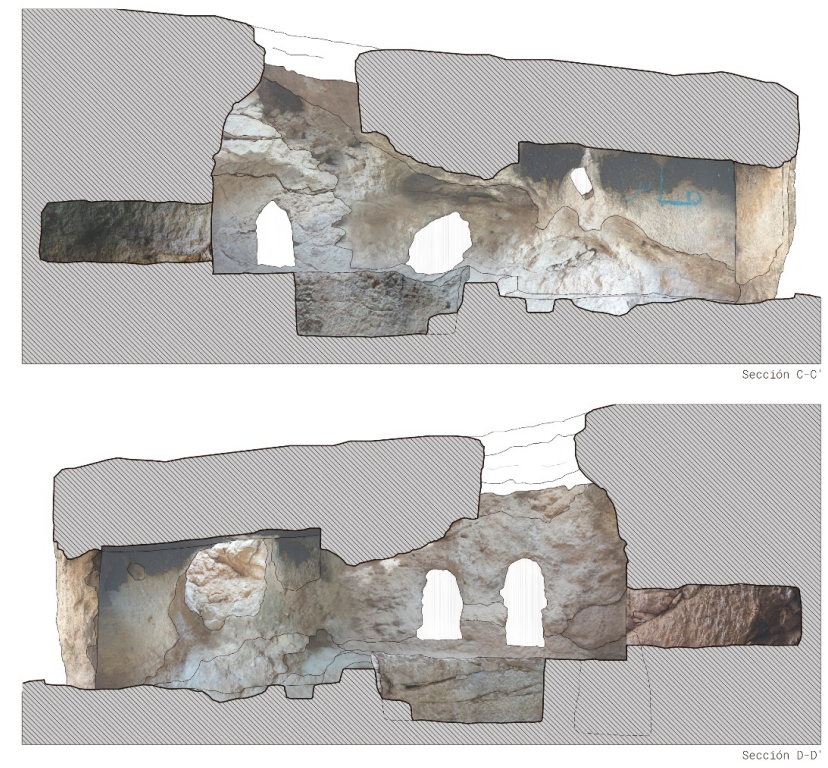

Figure 4. The vestibule: longitudinal sections of the space.
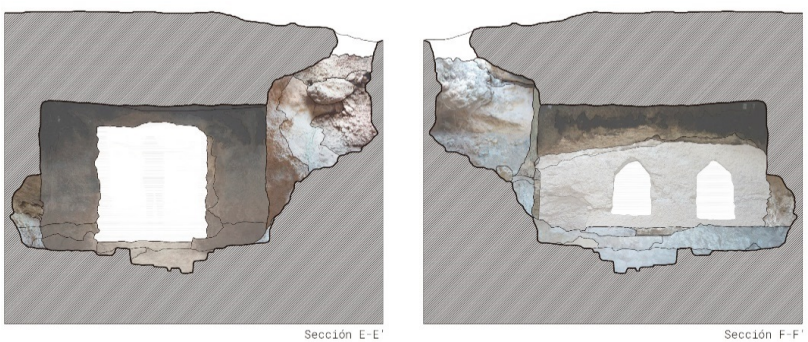

Figure 5. The vestibule: cross-sections of the space.

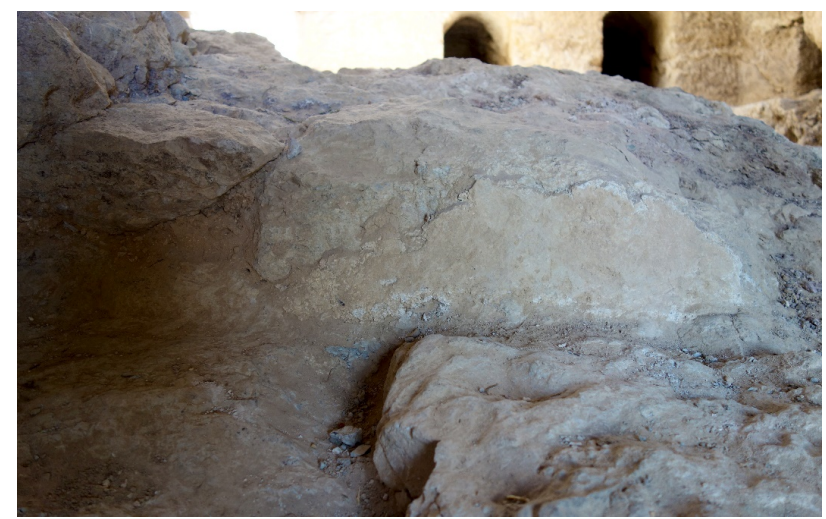

Figure 6 . White mortar at the bottom of the wall.
2.2.3 The vestibule (V1): The antechamber was a large square space $(3.30 \times 3.30 \mathrm{~m}$.$) , standing height (around 2 \mathrm{~m})$ with a horizontal roof. This space was optional in this kind of architecture, characteristically found in larger constructions, and served as a first element of the interior section and as a transition space between the entrance and the burial location (Kloner, Zissu, 2007). This easily accessible space was not sealed, had no funerary function, and was reserved for social congregations and the reading of elegies to bid farewell to the deceased (Figures 4 and 5).

The floor, in an advanced state of degradation, has undergone frequent looting, while the walls and ceiling are covered with soot from fires lit inside. In addition, part of the north wall, which is connected and opens up the interior space to the exterior, has collapsed.

This complicates the conservation of the tomb, as it creates new ways for the atmospheric and degradation agents to penetrate, accelerating the loss of heritage, and with it, physical access to information.

A series of noteworthy complementary elements can be observed here. On the east wall, $1.60 \mathrm{~m}$ from the original ground level, a small niche for an oil lamp $(0.25 \mathrm{~m}$ high by 0.50 $\mathrm{m}$ deep) can be observed. This was carved out with minimal removal of material in order to accommodate oil lamps to light the room (Magness, 2008) (Blétry, 2018) depending on the activities carried out, especially those of a social nature. Another rectangular opening can be seen in the floor below the entrance threshold; it was uncovered by lootings below original ground level and its origin may be unconnected as it is a later modification.

The existence of remains of a thin layer of white mortar on the wall which was thought to separate the rooms (Figure 6) confirms that this material was used to coat the entire space and may have been used throughout the complex, due to its continuity with the entrance of the burial chamber.

2.2.4 The entrance to the burial chamber (W1): The threshold to the access from the vestibule to the burial chamber was made up of a thick separating wall, approximately $1.00 \mathrm{~m}$ thick, containing the small entrance. Based on the geometric traces it was possible to establish measurements similar to the opening of nearby rock-cut tombs dating from the Second Iron Age, with a width and height of around $0.50-0.60 \mathrm{~m}$, a rectangular or almost square geometry lower down in contact with the floor (Figure 7). However, it is not known whether the recessing on this entrance was simple or ornamental as the partition was almost entirely in ruins, being the decorated one a reasonable supposition given the general architectural wealth. As in the antechamber, the white mortar remains in the vestibule strongly suggest that it was coated with a conserved layer between 0.01 and $0.015 \mathrm{~m}$ thick.

2.2.5 The closing stone: This entrance would have also included a closing or blocking stone, almost certainly made of harder rectangular rock, between approximately $0.20-0.30$ metres thick and made to fit accurately into the recessing of the opening (Hachili, 2004).

This is due to the private nature of the spaces it provided access to, as well as for hygiene and to avoid profanation, preventing the smell of putrefaction from seeping out and protecting from scavenging animals. 


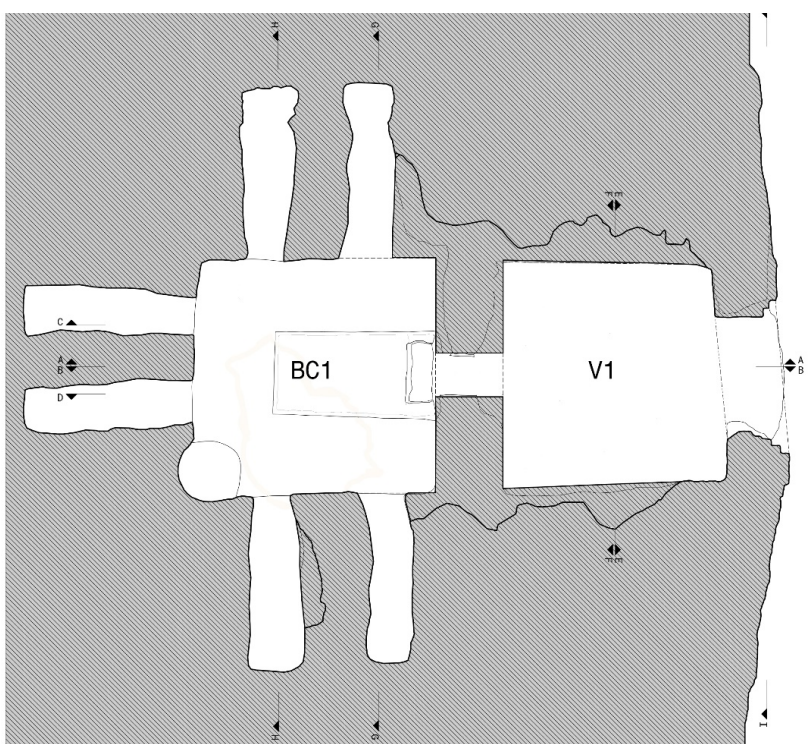

Figure 7. Spatial hypothesis of the grave.
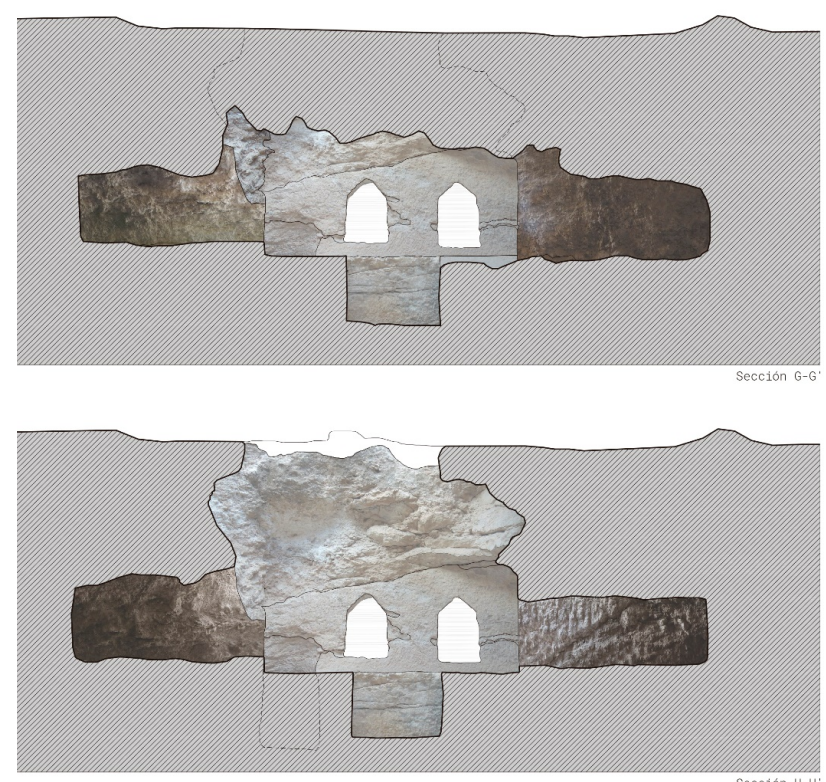

Figure 8 . The burial chamber: cross-sections of the space.

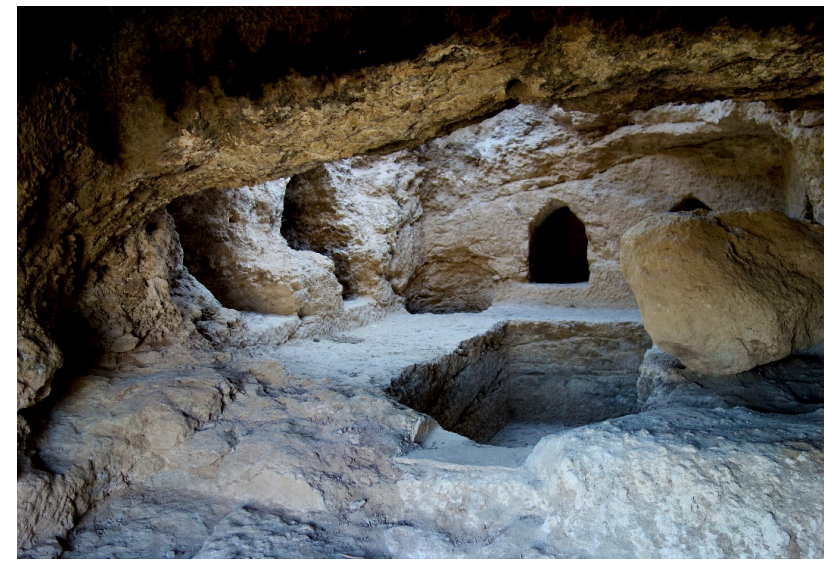

Figure 9. The burial chamber.
2.2.6 Standing pit and stair (SP1): The access leads to a single-step staircase $(0.30 \mathrm{~m}$ tread $\times 0.30 \mathrm{~m}$ riser $)$ and the central and geometrically rectangular standing pit (measuring $2.32 \mathrm{~m}$ high $\times 1.15 \mathrm{~m}$ wide $\mathrm{x} 0.95 \mathrm{~m}$ deep, allowing more than one relative to work at the same time) of the burial chamber, which was indispensable for manoeuvring inside as the ceiling height in this room was assumed to be around 1.30 m.

This ceiling has collapsed and the site is currently open to the sky, as well as and a large rock has become detached on the inside but has not been removed due to structural risks to the central pit as a result of serveral load alteration.

2.2.7 The burial chamber (BC1): The floorplan geometry of this main chamber is very similar to the antechamber or vestibule, measuring approximately $13 \mathrm{~m}^{2}(30 \%$ of the total of the complex), of which $2.75 \mathrm{~m}^{2}$ are the central pit (Figure 9). The main elements defining this chamber are varied with both benches and niches or 'kokhim'. In total, the configuration of three benches and six niches can be observed, implying a total burial capacity of nine simultaneous adult bodies.

The bone remains discovered confirm this was the site of a collective burial for at least fifteen people, including nine adults (Blétry, 2018).

2.2.8 Benches and shelves (BN): These are benches or beds along three of the four walls, one per wall and in a u-shape, as well as providing a functional shelf for the body placement works inside of the niche, with no noticeable depressions or shape variations in the centre (Figure 8). They are located at half height of the worker from the central pit, and were not designed as a place for transit, but a place to deposit remains which decomposed until the bones were ready to be transported to the ossuary.

In geometrical terms, these are continuous horizontal platforms in limestone, with no edge, 1.00 metre wide and between 2.50 and 3.00 metres long.

2.2.9 Loculi or 'kokhim' (LN): In addition, the niches or 'kokhim' make up the most important burial system in the complex. These openings could hold a whole body and were excavated perpendicular to the wall, enabling the execution of a greater number and in turn forming a larger, more efficient chamber (Figure 8). As it could be closed individually with standing stone closing slabs, it displayed more advantages in terms of hygiene, including easy maintenance, controlling the smell of decomposition until the replacement, collection and deposit in the ossuary.

It is worth highlighting that the niches were $0.22 \mathrm{~m}$ higher than the bench height of the chamber, which makes it possible to distinguish burial spaces and functions from the primary chamber.

The units are distributed equally opposite the u-shape benches on the three walls: two of them to the north, two to the east, and two to the west. The average separation between them is $0.75 \mathrm{~m}$ which made the excavation work viable as a smaller measurement could lead to the collapse of the intermediate rock partitions. 


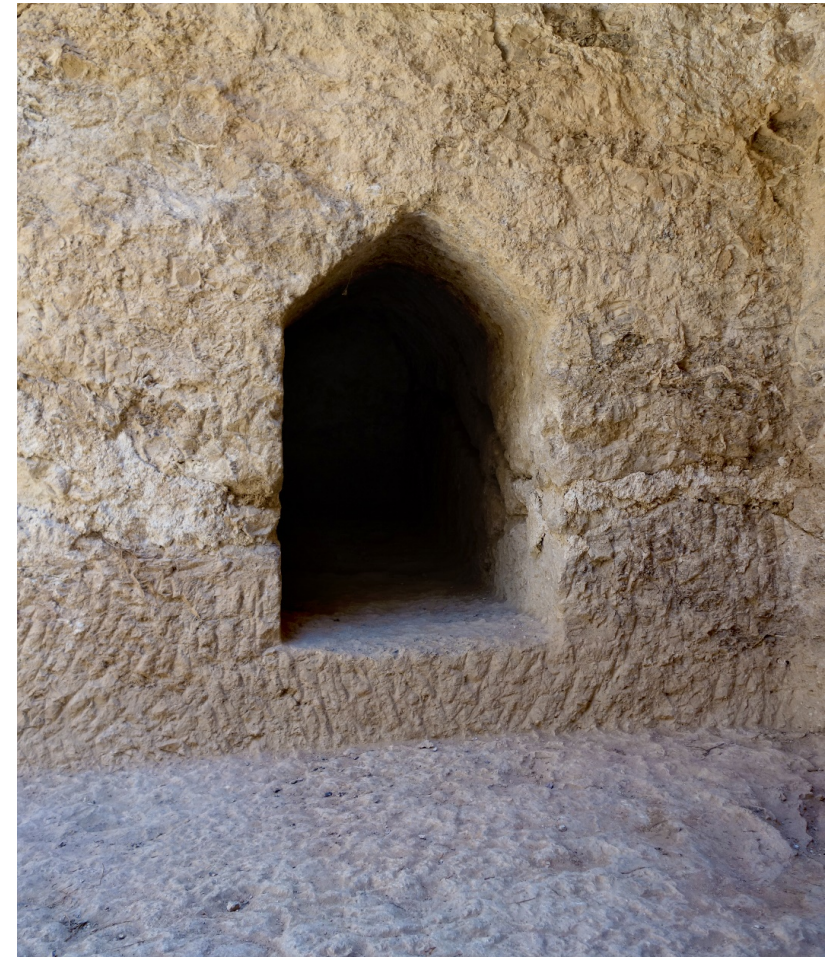

Figure 10. Loculi of the burial chamber.

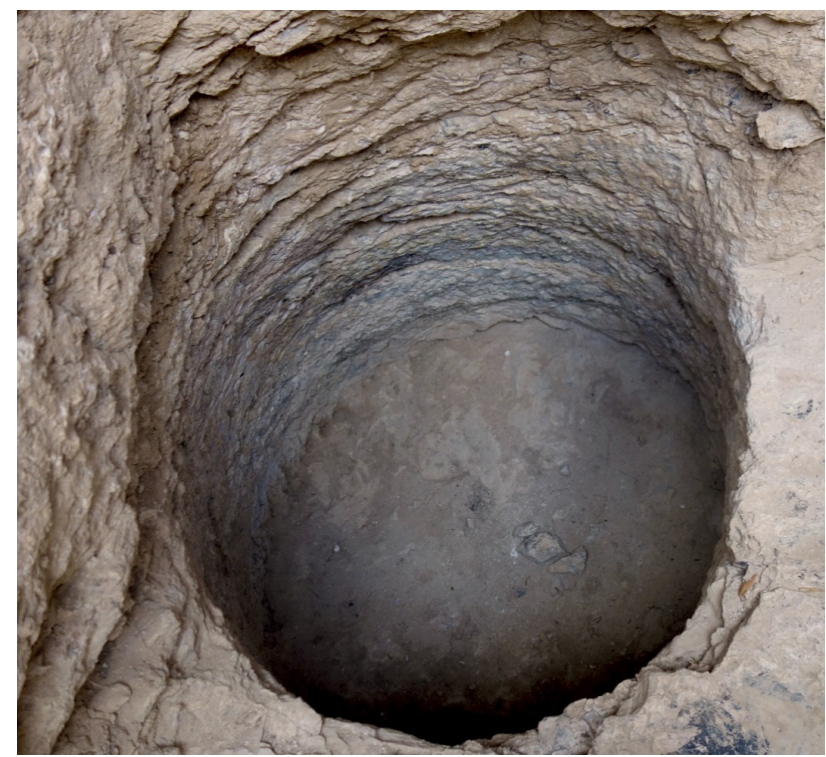

Figure 11. Collection pit of the burial chamber.

In terms of the geometry of the niche or loculi, these were dug out between $2.50-2.60 \mathrm{~m}$ long, while widths are around $0.60-$ $0.70 \mathrm{~m}$. The typical entrances are finished off with a triangle and a sharp edge at the top of the element similar to a classical pediment (Figure 10).

No recessed frame is observed so that in the closing system the stone was probably dropped in rather than carved to fit into the recess. A formal transition occurs from this triangle to the inside resulting in a vaulted ceiling with a constant height of $0.90 \mathrm{~m}$, and parallel side walls. The floor consolidation is completely horizontal in appearance. Given the size of the tomb, no cases of two-storey 'kokhim' or double-length 'kokh' were observed.
The degradation of the rock does not currently allow the formal visualization of the entreances of three of the niches, which only conserve their springer. In one of them the language has been completely lost due to successive collapses related with the original partition wall, making an architectural reading impossible.

2.2.10 Collection pit or repository (CP1): Opposite the entrance, on the northeast corner of the complex, is the collection pit for the tomb (Figure 11). It is located in the interior private area, commonly found in this type of burial (Kloner, Zissu, 2007) and used to deposit the bone remains from previous bodies when adding new corpses to the space. Despite the tomb's capacity for corpses this is the only collection pit, and it is located near and at the bottom of the niches for an easier service.

This is a deep pit with a horizontal floor which is proportional to the system. It is not known whether there was a stone slab leaning against the access to close it off. At its middle point it is $1.10 \mathrm{~m}$ deep, with a diameter of $0.90 \mathrm{~m}$ and a volume of $0.78 \mathrm{~m}^{3}$.

\section{CONCLUSIONS}

The survey and analysis of grave no. 26 at Tell Keila archaeological site highlighted its importance among the units studied and can be used to postulate a framework of features and elements of interest, establishing the relevant correlations with similar typologies observed locally and in contiguous regions.

The community was provided with a graphic database to learn about the entire case study, consisting of the most comprehensive and precise open knowledge system despite the limitations of the setting and latent threats, conserving the information in the event of physical losses in the historical document.

It offers a vision of funerary customs of different eras, displaying typological elements characteristic of the Second Iron Age, such as benches and shelves, as well as of later periods, such as loculi or 'kokhim', with a radically different configuration. Other smaller elements can be observed, such as the openings for oil lamps, unique within this archaeological site. It evidences the social tradition for saying farewell through initial congregation spaces, where size and design vary noticeably in relation to the burial chamber. This is an excellent example for observing many of the funerary elements of the time, with a few notable exceptions such as the courtyard (sloping or flat), the central rock pillars, the arcosolia, niches to hold several bodies and other specific elements.

For all these reasons tomb no. 26 is considered one of the most important in the site, as it is a source of information on occupation which is essential to understanding activities which took place there.

The survey of the architectural spaces found stresses the threats, both anthropic (looting) and natural (degradation agents) affecting the physical historic document. With regards to its state of conservation, the most notable aspects are the loss of volume and modification of the interpretation of the interior space, formerly divided by a rock partiction, as well as the serious collapses experienced and the accelerated deterioration due to exposure to degradation agents. 


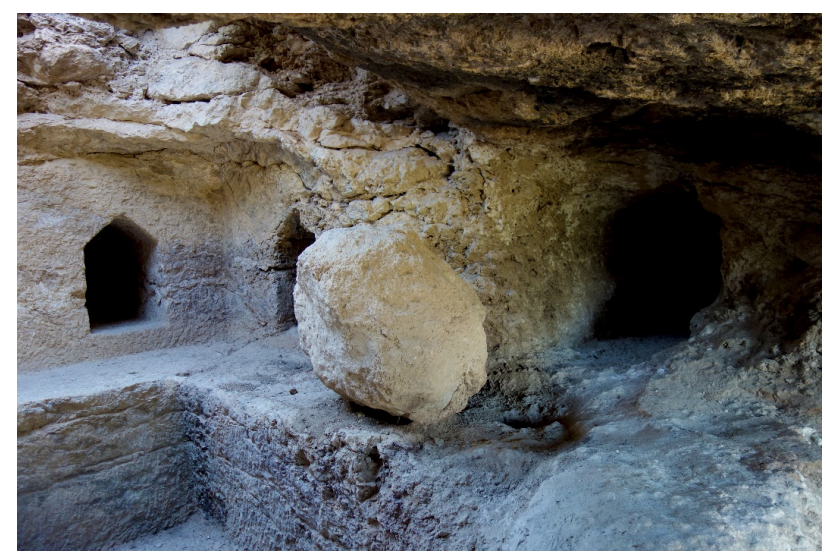

Figure 12. Fallen rock of the burial chamber.

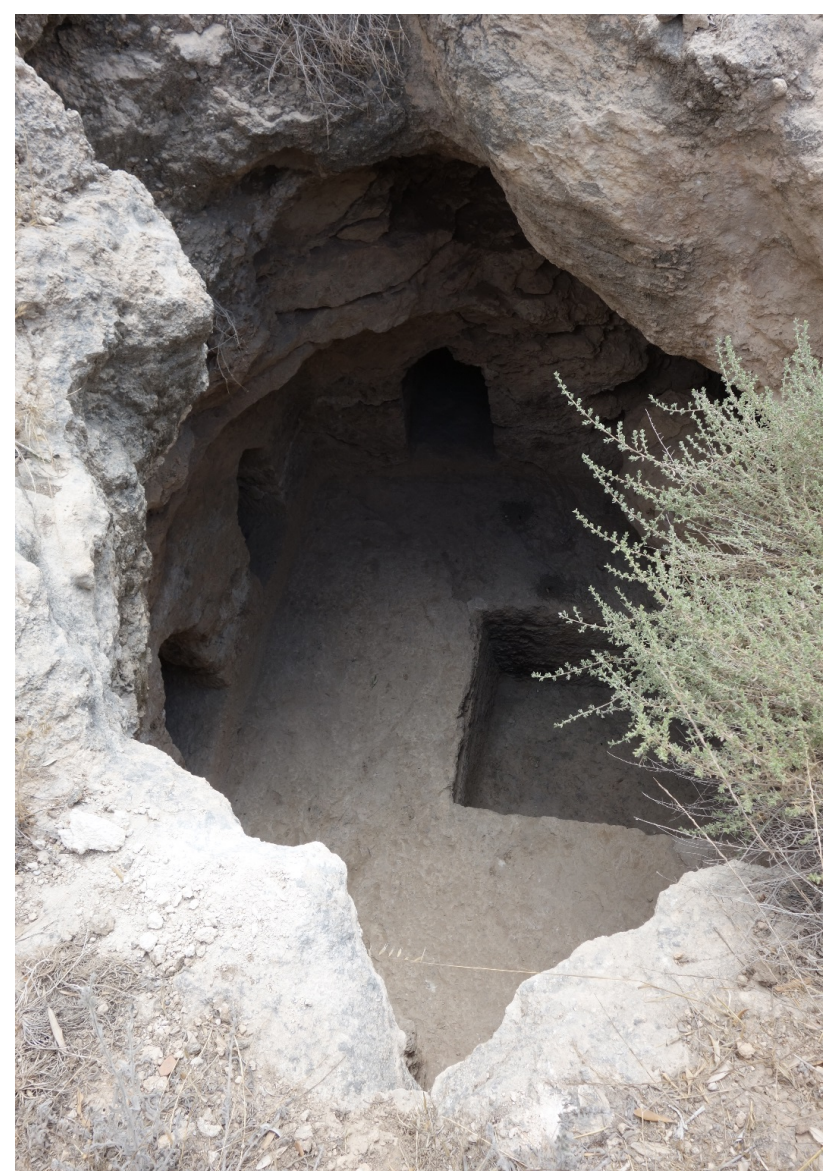

Figure 13. Openings of the burial chamber.

It is concluded that removing certain large fallen rocks could negatively affect the structural behaviour of the stone, causing new landslides, as could happen with the large rock on the bench, overhanging the central pit (Figure 12). The openings caused by collapse present a serious threat (Figure 13).

Furthermore, the survey serves as a basis for work on future research, dissemination and support to the developemnt of the archaeological activity recorded here from 2014. The recognition of its value from teams outside the area contribute to speeding up the valorization of the archaeological remains by promoting interest in them. Although it is a not a monument recognized by tourists, Tell shows the archaeological potential still to be discovered and handed down in the future.

\section{ACKNOWLEDGEMENTS}

This research project is developed within the collaboration of Camilla Mileto and Fernando Vegas with the archaeological project in Tell Keila, being developed under the direction of Sylvie Blétry with the support of EA 4424 CRISES, the Ministry of Tourism and Antiquities, the Scientific Council of the Montpellier University3, the team of the season carried out in 2018 and the local families participating in the excavations.

\section{REFERENCES}

Amit, D., Yezerski, I., 2001. An Iron Age II Cementery and Wine Presses at Nabi Danyal, Israel Exploration Journal 51, 171-193.

Association d'Échanges Culturels Hébron-France, 2016. Hébron et ses environs. Studio Alpha, Al-Ram, Jerusalem, 78.

Blétry, S., Duval, H., Girardi, C., Loupmon, T., Rjoob, A., 2018. Tell Keila, résultats de quatre années de recherches. Syria. Archéologie, art et histoire 95, 213-243.

Blétry, S., 2018. Fouilles de Tell Keila (Territoires Palestiniens). Arthist. Le Magazine du départment d'histoire de l'art d'archéologie 1, 5-6.

Bloch-Smith, E., 2013. Death and Burial, Bronce and Iron Age in Master, D. ed The Oxford Encyclopedia of the Bible and Archaeology, Oxford University Press, Oxford.

Corner, C., Kitchener, H., 1881-1883. The survey of western Palestine: memoirs of the topography, orography, hydrography, and achaeology, Committee of the Palestine exploration fund, London.

Hachili, R., 2004. Jewish Funerary Customs, Practices and Rites in the Second Temple Period, Supplements to the Journal for the Study of Judaism 94, 29-73.

Guérin, V., 1869. Description géographique, historique et archéologique de la Palestine, Judée, III, Paris.

Kloner, A., 2000. Survey of Jerusalem, the Southern Sector (Archaelogical Survey of Israël), Israel Antiquities Authority Publications, Jerusalem.

Magness, J., 2008. The Oil Lamps from the South Cementery, The necropolis of Bet Guvrin-Eleutheropolis, Israel Antiquities Authority Publications, Jerusalem, 121-177.

Kloner, A., Zissu, B., 2007. The Necropolis of Jerusalem in the Second Temple Period (Interdisciplinary Studies in Ancient Culture and Religion 8), Peeters Pub, Leuven, 12-99.

Yezerski, I., 1997. Burial Caves in the Hebron Hills, 'Atiqot XXXII 21-36.

Yezerski, I., 1999. Burial-Cave distribution and the Borders of the Kingdom of Judah toward the end of the Iron Age. Tel Aviv, $26: 2,253-270$.

Yezerski, I., 2013. Typology and Chronology of the Iron Age IIIII Judahite Rock-cut Tombs, Israel Exploration Journal 63, 5077. 